\title{
Diagnóstico sobre a sociedade e a violência na escola
}

\section{Diagnosis on society and violence in school}

Rosemary Tourinho Pereira' Maria Eleusa Montenegro ${ }^{2}$ Ana Regina Melo Salviano ${ }^{3}$

1 Graduada em Letras no Centro Universitário de Brasília - UniCEUB. E-mail: rosetourinho@ gmail.com.

2 Doutora em Educação pela UNICAMP, PósDoutora pela UnB e professora do Centro Universitário de Brasília (UniCEUB). E-mail: memontenegro@terra.com.br.

3 Mestre em Educação pela FE/UnB; pedagoga; orientadora educacional; administradora escolar; professora aposentada da SE-DF; professora do UniCEUB e coordenadora do NIVA. Email: ana.salviano@uniceub.br. 


\section{Introdução}

A globalização trouxe uma imensa transformação social, apresentando um novo mundo. Incertezas, desafios, competitividades, vulnerabilidades estão presentes a todo instante, em todos os segmentos sociais, colocando em evidência iniquidades e desigualdades marcantes. Essa nova sociedade vem trazendo uma imensa modificação nas relações de poder e de produção que resultam numa transformação significativa e no surgimento de uma nova cultura.

A sociedade brasileira vem se deparando com um aumento significativo da violência, sobretudo da violência escolar, sendo diversos os episódios de agressões verbais e físicas envolvendo os atores desta comunidade, fatos que despertam a atenção da sociedade em geral.

Atualmente, a violência na escola constitui-se como um dos principais males da sociedade é, portanto, reflexo de vários setores, quer sejam o político, o econômico, o social e o cultural. Ao observar a questão educacional, percebe-se que a violência é responsável em parte pela evasão escolar, por afastamento de professores (licença médica), causado por doenças psicossomáticas (stress), pelo baixo rendimento dos alunos, enfim, pelo medo e insegurança que acometem as escolas na maioria das regiões do país. Trata-se, portanto, de um problema da humanidade no qual, dialeticamente, ao mesmo tempo em que é causa, é também consequência de inúmeros problemas sociais com profundos reflexos no ambiente escolar. Assim, vive-se num círculo vicioso em que a violência urbana fomenta a violência familiar que, por sua vez, alimenta a violência na escola. Esta se manifesta de várias formas e envolve as pessoas, quer sejam como vítimas, quer como agressoras. $\mathrm{O}$ ambiente escolar deve estar voltado para a formação do homem, do processo de ensino-aprendizagem, da socialização, do respeito mútuo, da troca de experiências entre seus participantes, dos alunos, dos professores, dos funcionários e da comunidade.

Percebeu-se que conceituar "violência" não é uma tarefa fácil, pois é considerada palavra complexa e ambígua no meio cultural. Em estudos realizados por Waiselfisz e Maciel (2003), a violência pode ser considerada como parte da própria condição humana, manifestando-se de acordo com os arranjos, mudanças e as várias transformações que a sociedade apresenta.
Segundo o Dicionário Houaiss de Língua Portuguesa (HOUAISS; VILLAR, 2009, p. 1948), violência significa a "ação ou efeito de violentar, de empregar força física (contra alguém ou algo) ou intimidação moral contra (alguém); ato violento, crueldade, força”.

A escola e seus atores têm assumido até então a postura de vítima, muitas vezes, alheia ao fenômeno, na esperança de que a sociedade e suas instâncias (polícia e justiça) sejam responsabilizadas, eximindo-se assim dessa culpa. Percebe-se, no entanto, que não se concebe um curso de formação dos futuros profissionais da educação, que deverão atuar na rede particular e pública de ensino. O presente trabalho pretende promover uma discussão-reflexão para além da formação didático-pedagógica, durante o processo de formação do professor. Pretende-se discutir o tema de forma direta, clara e objetiva e, ao mesmo tempo, após esta diagnose, traçar algumas ações que possam colaborar para a solução da violência na escola.

Este trabalho teve como tema/objeto de pesquisa analisar a violência na Região Administrativa de Santa Maria em uma escola de Ensino Médio, tomando como referência tratar-se de uma escola pública.

Foi investigada a violência em seus diversos aspectos, dentre os quais, aquele fruto das condições socioeconômicas e político-culturais da sociedade que, inevitavelmente, irá refletir no ambiente escolar.

Trata-se de uma pesquisa tendo como pressuposto a possibilidade de contribuir para o processo de superação da relação violência escola/comunidade. Acredita-se que, com os resultados deste trabalho, possam-se sugerir alternativas de soluções para escolas de outras regiões de Brasília.

\section{Objetivos e Hipóteses}

O objetivo geral desta pesquisa é conhecer as causas e situações de violência nas escolas, levantando medidas de solução ao problema.

Os objetivos específicos são:

a. Diagnosticar situações de violência física, material e emocional nas escolas.

b. Identificar as causas e consequências da violência no contexto escolar. 
c. Indicar uma proposta de ação para colaborar na solução dessa problemática.

Ressalta-se que, por este trabalho tratar-se de uma pesquisa de cunho qualitativo, não havendo obrigatoriedade da elaboração de hipóteses, uma vez que este tipo de trabalho promove a oportunidade, inclusive, do surgimento de novas hipóteses durante o trabalho, podendo ter o seu curso também alterado, desde que seja para se obter melhores resultados, atingindo assim seus objetivos, ele tem algumas hipóteses prováveis que, se espera, sejam confirmadas ao final desta pesquisa:

É possível conhecer sobre a violência por meio de pessoas da comunidade escolar e especialistas no assunto.

O investimento na autoestima do aluno e dos profissionais da educação poderá alterar comportamentos agressivos no ambiente escolar.

As pessoas da comunidade escolar apresentam propostas eficazes na prevenção e combate à violência.

A escola da rede pública apresenta muitos casos de violência.

\section{Metodologia}

A abordagem metodológica do trabalho foi uma pesquisa de cunho qualitativo. Entretanto, também serão utilizados elementos da pesquisa quantitativa, quando for necessária maior visibilidade numérica dos dados. A pesquisa qualitativa, segundo Minayo (1995, p. 21-22):

se preocupa, nas ciências sociais, com um nível de realidade que não pode ser quantificado, ou seja, ela trabalha com o universo de significados, motivos, aspirações, crenças, valores e atitudes, o que corresponde a um espaço mais profundo das relações dos processos e dos fenômenos que não podem ser reduzidos à operacionalização de variáveis.

Nesse sentido, Bogdan e Biklen (1994) destacam que a investigação qualitativa tem na sua essência cinco características fundamentais: a fonte direta dos dados é o ambiente natural, em que o investigador é o agente principal no recolhimento desses mesmos dados; os dados que o investigador recolhe são de caráter essencialmente descritivo; os investigadores que usam os métodos qualitativos interessam-se mais pelo processo em si do que propriamente pelos resultados; a análise dos resultados é feita de maneira indutiva; e o investigador interessase em tentar entender o significado que os participantes atribuem às suas experiências acima de tudo.

Ainda quanto à pesquisa qualitativa, Zinato $\mathrm{e}$ Montenegro (2004) enfatizam que não se trata apenas de observar ou de descrever. O problema consiste em saber como alcançar determinados efeitos, conceber objetos, organizações, práticas educacionais e suportes materiais com características e critérios aceitos pelos grupos interessados. Tal concepção possui uma dimensão conscientizadora.

O cenário da pesquisa foi uma escola da Região Administrativa de Santa Maria no Distrito Federal, onde foram colhidos dados com relação à violência no Ensino Médio.

Os participantes desta pesquisa foram os especialistas sobre o assunto: diretor de escola (1); professores (2); coordenador pedagógico/orientador educacional (1); membro do Conselho Tutelar (1); Organização Não Governamental (ONG) (1) que trabalha com o assunto; e representante da comunidade em geral (1).

O Conselho Tutelar é composto por membros eleitos pela comunidade para acompanharem as crianças e os adolescentes, decidindo em conjunto sobre qual medida de proteção é ideal para cada caso. "O Conselho Tutelar é órgão permanente e autônomo, não jurisdicional, encarregado pela sociedade de zelar pelo cumprimento dos direitos da criança e do adolescente definidos na lei. Art. 31 do Estatuto da Criança e do Adolescente" (Representante da comunidade).

Para tanto, foram realizadas entrevistas com as pessoas e entidades acima mencionadas, objetivando identificar e conhecer o fenômeno da violência na escola e a forma que se apresenta. A entrevista é definida por Haguette (1997, p. 86) como um "processo de interação social entre duas pessoas no qual uma delas, o entrevistador, tem por objetivo a obtenção de informações por parte do outro, o entrevistado".

Pretende-se que os resultados da pesquisa possam contribuir com outras instituições escolares públicas do Distrito Federal, colaborando, assim, para a diminuição do problema da violência escolar. 


\section{Análise e Discussão de dados}

Participaram deste trabalho dois professores, uma diretora, um orientador pedagógico, uma representante da comunidade, um representante de uma ONG e um representante do Conselho Tutelar, sendo ao todo três mulheres e quatro homens, todos da Região Administrativa de Santa Maria no Distrito Federal.

Os professores, a diretora e o coordenador atuavam em uma escola pública em Santa Maria, com poucos anos de funcionamento, que atende alunos do Ensino Médio, em uma região onde prevalece uma população de baixa renda.

Os participantes da escola - professores, orientador e diretora - possuem graduação e especializações, os demais entrevistados - representantes da ONG e comunidade - são graduados e o representante do Conselho Tutelar possui Ensino Médio. Suas idades variaram entre 30 e 60 anos. Quanto ao tempo de serviço, estavam entre dois e vinte anos.

As categorias selecionadas para este trabalho foram:

a. Formas de violência.

b. Causas da violência.

c. Consequências da violência.

d. Medidas de prevenção e de diminuição da violência.

e. Papel da escola diante da violência.

f. Papel dos pais, da comunidade e do Estado.

g. Preparação para lidar com a violência.

A seguir serão analisados e discutidos os dados, dentro de cada uma das categorias selecionadas.

\subsection{Formas de violência}

Quando questionados sobre as mais frequentes manifestações de violência na escola, seus representantes apontaram o bullying, as ameaças e as agressões verbais. "Entre alunos: bullying e brigas por motivos fúteis. Contra professores: ameaças, intimidações e 'vias de fato' (raramente) provocadas por alunos e pais", afirmou o professor A.

Já sobre os tipos mais frequentes de violência na comunidade, os representantes apontaram o abandono de incapaz, a dependência química, o bullying, as brigas entre gangues e os assassinatos de jovens. Porém, o representante da ONG destacou que as crianças e os adolescentes não podem ser estigmatizados por uma violência, na qual não são os responsáveis, assim salientando:

a violência não é gerada pelas crianças ou adolescentes, eles só são reflexos de uma sociedade que se pauta na competitividade, onde cada um tem que superar o outro, ser melhor que o outro, e querem colocar a culpa nos adolescentes, devido serem o lado mais fraco de toda essa questão, temos que deixar de hipocrisia e ver que a raiz da violência não está em nossas crianças/adolescentes, e sim na forma de organização estrutural de nossa sociedade (Representante da ONG).

De maneira coerente em relação às respostas obtidas, Santos (2001) retrata que a escola está inserida neste fenômeno social e sofre com os vários tipos de violência em seu interior e periferia. Oliveira (2008) ainda reafirma os tipos de violência mais frequentes, dizendo que a escola tem aparecido nos noticiários como um cenário de agressões, ameaças, uso de armas, consumo de drogas, furtos e roubos.

Os professores já presenciaram atitudes de violência e também já foram vítimas de alguns tipos de violência, como agressões verbais e ameaças contra a integridade física. "Ameaças contra a integridade física são, de certo modo, constantes" (Professor A). Cubas (2006), nesse sentido, afirma que os professores devem ser capazes de intervir e de evitar conflitos e tratamentos violentos.

\subsection{Causas da violência}

No que diz respeito às causas da violência, os fatores apontados por todos os participantes foram a falta de investimento na educação, o ambiente familiar violento, o meio social, o alcoolismo, a impunidade nacional, a pobreza, as drogas, a desestrutura familiar, o preconceito, entre outros.

Um dos participantes disse não perceber a violência na escola como algo alarmante, diz ser mais exagero dos meios de comunicação. O que está faltando, segundo esse representante, é diálogo entre professor e aluno, assim ressaltando:

A violência não está só no ambiente escolar, está em toda nossa estrutura social e a escola faz parte dessa estrutura. Não vejo tanta violência o quanto dizem! Violência tem. Mas não tão crítica com se divulgam nos meios de comunicação, participo do ambiente escolar e não percebo 
essa violência toda, garotos que são vistos como problemáticos nas escolas são os mais criativos e os motivos de suas inquietações é por falta de diálogo construtivo entre a comunidade escolar (professores, alunos, pais), pois os "diálogos" que se vê nesses ambientes são impositivos hierarquizando os relacionamentos, que professor é professor, aluno é aluno e não falam a mesma língua, não têm diálogo horizontal (Representante da ONG, grifo nosso).

Segundo Oliveira (2008), coerente com parte dos dados dos participantes, a desigualdade social que atinge as relações humanas é, certamente, um dos fatores que contribuem de maneira marcante à degeneração do comportamento humano.

De acordo com os participantes, os professores e orientadores não podem ser considerados desencadeadores de violência, pois eles estão no ambiente escolar para mediar os conflitos existentes, exercitando o respeito e a tolerância, promovendo a paz para o ambiente escolar. Porém, para eles, o governo pode desencadear a violência.

Em desacordo com as respostas, Fante (2005) diz que, na visão dos docentes, os alunos é que são violentos, como se professores, diretores, coordenadores pedagógicos fossem isentos de práticas violentas. Estes não se percebem desencadeadores de atitudes violentas. Contudo, contrário ao que foi falado por alguns participantes, um professor fez o seguinte comentário: "sim, professores despreparados para a função do magistério podem piorar a situação na escola. Pode haver discriminação por parte do profissional em relação aos alunos violentos" (Professor B).

Para o participante da comunidade, o mundo contemporâneo ajuda por meio de seus novos modelos de família e de ações e pode ser um dos responsáveis por esta situação, mas é difícil apontar um responsável, sendo que a família e o Estado também são responsáveis.

\subsection{Consequências da violência}

Quanto às consequências, foram citados a evasão escolar, a descrença nas instituições e nas pessoas, a desmotivação, a agressividade dentro e fora da escola, a desvalorização da escola e dos professores, a falta de identidade, o baixo rendimento, a infrequência, os vícios, dentre outros.

Sobre esse assunto, Candau, Lucinda e Nascimento (1999, p. 42) afirmam que:

numa sociedade marcada pelo individualismo, pela apatia social, pela falta de solidariedade, pela confusão no que se refere ao certo e o errado, certamente não constitui tarefa fácil estabelecer limites e/ou construir regras disciplinares. Pais e educadores, não querendo repetir, com seus filhos e alunos, o modelo de educação autoritário em que, muitas vezes, foram criados, têm dificuldades em estabelecer limites e regras de disciplina.

O orientador pedagógico afirmou que "as consequências são a evasão escolar, a desmotivação, a agressividade dentro e fora da escola e outros fatores que levam ao círculo vicioso da violência". Somando-se a isso, os alunos perdem o interesse pelas questões relativas aos estudos, desencadeando o fracasso escolar.

\subsection{Medidas de prevenção e diminuição da violência}

Todos os participantes salientaram que a prevenção à violência ocorre no cotidiano de sala de aula, devendo, para isso, a escola promover palestras, debates, buscando conscientizar o aluno sobre a gravidade do tema, elaborar projetos abordando o tema e tentar manter a ordem em sala de aula, com vigilância constante. De acordo com os Representantes da comunidade e da ONG, devem ser tomadas medidas preventivas em concordância com o Estatuto da Criança e do Adolescente (ECA) e desenvolvidos trabalhos em conjunto, nos quais todos se responsabilizem pelos fatos e incentivo ao esporte, cultura e lazer para crianças e jovens.

Um meio saudável de prevenção à violência é o desenvolvimento de programas de esporte, cultura e lazer, que, educativamente, colocam no centro do projeto a valorização da pessoa, e não a atividade em si. Inclusive a escola cedendo espaço à comunidade para a realização de eventos nesse sentido, incluindo, nesses programas a questão do combate às drogas, visto que estas geram a violência. Estejam também, nesses programas, ações que valorizem as relações familiares e incentivem os valores humanos. Sendo que a forma de desenvolver ações preventivas vai depender muito de cada realidade socioeconômica e cultural da comunidade em que se atua (Representante da comunidade).

Variados foram os projetos apresentados pelos participantes. Na escola, os desenvolvidos não estão ligados à violência, mas os professores desenvolvem o tema com os alunos em sala de aula. "Como a comunidade escolar é relativamente tranquila, os projetos giram em torno de outras demandas. Contudo os docentes, em suas áreas e/ou disciplinas, sempre trabalham com essa temática" (Direção Escolar). Os professores pensam que atividades relacionadas ao esporte, jogos lúdicos e passeios 
podem contribuir para a prevenção da violência, porém estes profissionais desejam mais motivação, sem serem tão sobrecarregados. Torna-se necessário, de acordo com os participantes, o desenvolvimento de projetos na escola como forma de prevenção à violência.

Percebe-se que a escola e seus educadores passam por várias transformações e que trabalhar com a violência nas escolas exige de seus profissionais atitudes mais concretas para que possam modificar a realidade, as relações interpessoais entre professores e alunos, a família, a própria comunidade e, sobretudo, especial atuação para realizar a integração da escola/ da família/ da comunidade.

Além das atividades que podem ser desenvolvidas, há propostas e soluções que, no entender de Fante (2005, p. 209), visam à melhoria da relação entre escola, professores e alunos:

Para alcançarmos êxito na redução da violência, precisamos, primeiramente, conquistá-la na escola, por ser lá que os primeiros sinais de violência se manifestam entre os alunos. Devido ao seu poder propagador e multiplicador, a escola deve ensinar os alunos a lidarem com suas emoções para que não se envolvam em comportamentos violentos, transformando-os em agentes disseminadores de uma cultura de paz que se estenda aos seus demais contextos de vida.

O Conselho Tutelar aplica medidas de prevenção com a Assistência Social, o Posto de Saúde, o Programa de Distribuição de Rendas e o Acolhimento Institucional, envolvendo os dependentes químicos, a família, a igreja, a sociedade e a ONG. Nele, são desenvolvidos projetos culturais, oficinas, cultura do hip hop, tendo como metodologia a educação para todos.

As propostas de combate e prevenção baseadas nos dados coletados fazem uma série de recomendações nas esferas do lazer, da interação entre escola, família e comunidade, cuidados com o estado físico e a limpeza do estabelecimento.

\subsection{Papel da escola diante da violência}

A escola possui um papel primordial que é o de preparar o futuro cidadão para atuar no meio social e cultural, aspectos estes tão essenciais e importantes para o desenvolvimento humano e sua construção, enquanto sujeitos históricos e atuantes.

Portanto, a escola pode levar em consideração que deve perseguir a ideia de desenvolvimento pleno dos in- divíduos para viver em sociedade e assim minimizar o conflito presente em qualquer agrupamento de pessoas, assumindo o papel de esclarecedora, conscientizadora, libertadora e transformadora.

Para o diretor, a escola possui uma postura bem rígida quanto à violência e está de acordo com a Secretaria de Educação, procurando inserir a família no processo para que assuma suas responsabilidades. Quanto ao questionamento se existe na escola a figura do professor agressor, ele afirmou que este ainda não foi identificado, que não ocorreu reclamação neste sentido, mas que, muitas vezes, os alunos têm medo de denunciar. "Essa situação ainda não foi vivenciada pela equipe gestora, pois creio que há um receio, por parte da comunidade discente, de formalizá-la quando ocorre em sala de aula", estas são palavras do orientador pedagógico. "Após solicitação da direção da escola, o SOE pode conversar com o professor para entender os motivos que o levaram a esta atitude. Orientar o professor para buscar ajuda especializada no caso de algum desconforto emocional" (Participante da coordenação escolar).

Com relação à questão de onde partia a violência, se era entre aluno-aluno, aluno-professor ou mesmo professor-professor, a resposta foi taxativa de que era entre os alunos. Ao contrário dos dados dos participantes, Royer (2002, p. 251-266) apresenta que a educação e a escola têm papel importante na prevenção e nos meios de contornar a violência e os comportamentos agressivos que são evidenciados em alguns jovens; e que os professores devem ficar atentos, a fim de que possam intervir, de maneira ativa e não reativa, nos problemas de violência na escola.

Questionados sobre qual o papel da educação diante da violência, todos os participantes se posicionaram, à exceção da diretora da escola. Os dados coletados enfatizaram que se deve promover a reflexão das atitudes violentas em parceria com a família; que a escola não tem estrutura para trabalhar sozinha essa questão; que se deve utilizar método pedagógico mais ativo, programas educacionais, ensino religioso, para formar e educar os jovens.

O mínimo que se exige da escola é que honestamente operacionalize os Parâmetros Curriculares Nacionais $(\mathrm{PCN})$, que incluem os temas transversais e o ensino religioso, e incentivem a desenvolver programas educacionais que proporcionem a formação de cidadãos críticos e responsáveis diante de uma sociedade cheia de 
problemas, entre eles das drogas que gera tanta violência, dentre outros problemas (Participante da comunidade).

Os dados apresentados remetem a Fante (2005), quando esta diz que o fenômeno não pode se alastrar e, para isso, os profissionais da educação precisam estar preparados e capacitados para conseguir atuar de maneira eficaz.

\subsection{Participação dos pais, o papel da comunidade e do Estado}

De acordo com o diretor da escola, os pais participam minimamente na vida escolar dos filhos e somente comparecem à escola quando são chamados pela direção. Nessa realidade, a ausência da família influencia amplamente no contexto de violência.

Sendo a família o modelo inicial de socialização, ela deve construir um modelo positivo para a criança, pois a relação de afeto com as figuras paternas e maternas são os registros iniciais de experiências emocionais que repercutem na formação da personalidade do indivíduo.

Se os pais não estão presentes na vida escolar de seus filhos, provavelmente, estas crianças se sentem abandonadas no contexto escolar, ficando, assim, vulneráveis à violência. "A participação de pais na vida escolar dos alunos é mínima, praticamente só comparecem quando 'convocados'. Certamente, essa ausência da família na escola colabora, e muito, para esse contexto de violência" (Direção escolar, grifo do autor).

Coerentemente com essa análise, Fante (2005) explica que os fatores externos à escola são vitais para a formação da personalidade da criança, porque toda a influência que a criança adquire está no contexto familiar. Nesse sentido, de acordo com Royer (2002, p. 251-266):

\begin{abstract}
o ambiente familiar é uma variável imprescindível na promoção do desenvolvimento e manutenção das capacidades que embasam uma boa integração social. O trabalho com as capacidades dos pais desempenha um importante papel no sucesso das intervenções propostas pela escola para tratar dos comportamentos agressivos.
\end{abstract}

Para os participantes, somente o Estado não é suficiente no combate à violência e é dever também da família, das escolas, da igreja, da comunidade e da sociedade em geral. "O Estado é omisso, o Estado só está presente como órgão de repressão, e como repressão não combate violência, essas ações é ineficaz, ações essas que vem num caráter de marginalização de nossa juventude" (Participante da ONG).
Quanto à importância da comunidade, o diretor enfatizou que é de suma importância o envolvimento de todos os segmentos da comunidade, principalmente a família.

Os participantes responderam que há, em alguns casos, a rejeição da família ao aluno problemático, por estar cansada das atitudes da criança, pré-adolescente e que, muitas vezes, a família espera que outras pessoas façam o seu papel de pais. No caso da rejeição por parte dos orientadores e professores, foi explicitado que eles não rejeitam os alunos violentos, mas que, às vezes, ficam desmotivados por não conseguirem alcançar seus objetivos com determinados alunos. Porém, alguns professores preferem manter distância para preservar sua segurança. O instinto de autopreservação natural em todos os seres faz com que muitos professores tentem manter uma distância de segurança a esse tipo de aluno (Professor 1). Em relação a esse questionamento, Colombier (1989) afirma que a falta de autoridade tanto familiar quanto educacional tem suas bases no contexto familiar.

Para constatar essa rejeição ao aluno violento, tomar-se-á como base as palavras de Arendt (1994) quando diz que a escola está vivendo uma crise de autoridade e os professores na maioria dos casos não sabem o que fazer.

\subsection{Preparação para lidar com a violência}

Alguns dados encontrados demonstram que em parte os professores encontram-se preparados, porque, com as experiências do dia a dia, acabam aprendendo a contornar os problemas que surgem. Outros docentes destacaram que não foram preparados para lidar com esses tipos de situações. Um dos participantes afirmou que "na formação acadêmica falta muito o contato com a escola real, o aluno real e sobra o ideal". Outro professor respondeu que quase não há treinamento para ensiná-los a lidar com esse tipo de situação e que, além disso, há outras crianças em sala para serem orientadas.

Constatou-se em alguns depoimentos o medo dos professores de lidar com determinadas situações, quando acontecem nos arredores da escola, em especial, os problemas com o tráfico de entorpecentes. Nesse sentido, segundo matéria publicada Revista Veja (1996), os alunos indisciplinados atormentam tanto os professores que estes não conseguem controlar a bagunça na sala de aula.

Os professores, realmente, não foram preparados para lidar com esse fenômeno e acabam por utili- 
zar de suas experiências para contornar as situações de violência.

\section{Considerações Finais}

Atualmente, há uma grande preocupação, por parte dos educadores, com a violência que se alastra no contexto escolar. Entretanto, o termo violência é bastante amplo e gera diversas discussões a respeito do seu conceito, das suas causas, da sua natureza e da delimitação de seu objeto.

Esta pesquisa demonstrou que as escolas estão despreparadas para lidar com esse problema e que os professores não possuem uma formação adequada para lidar com o fenômeno. De modo geral, ainda falam em projetos, como se a violência devesse ser trabalhada pontualmente e não durante todo o tempo.

O sistema educacional tem como obrigação nutrir as relações interpessoais. No entanto, quando ocorrem conflitos entre os indivíduos, a escola acaba se omitindo para diminuir sua responsabilidade quanto à ocorrência e à sua eliminação. Também, para se protegerem de escândalos ou até mesmo por medo de vingança por parte dos agressores, preferem silenciar a denunciar os atos de violência, atribuindo as causas a fatores externos, para eximirem-se da culpa.

Podem ser observados os tipos de violência praticados tanto na escola como nos seus arredores, um desses tipos é o bullying que surgiu nas últimas décadas para classificar um tipo de violência que tem aparecido, principalmente, nas escolas, como reflexo da sociedade. Embora não seja um fenômeno novo, tem sido estudado recentemente, em função da proporção atual, na qual o agressor é sempre alguém em situação de vantagem em relação ao agredido.

De acordo com o resultado da pesquisa realizada, foi possível confirmar as hipóteses inseridas neste trabalho, pois pôde ser observado que é possível conhecer sobre o fenômeno violência por meio de pessoas da comunidade escolar e de especialistas no assunto. Observa-se, também, que profissionais preparados e dispostos a transformar o contexto escolar podem alterar os comportamentos agressivos no ambiente escolar.
Ainda, de acordo com a pesquisa, percebeu-se que as pessoas da comunidade escolar apresentam, de forma eficaz, propostas para prevenir e combater a violência, como programas de esportes, de lazer e de cultura. Observa-se também a realidade, na qual se insere a escola pública nos dias atuais, ambiente com variados tipos e casos de violência como furtos, agressões e bullying.

Por meio deste trabalho, conclui-se que acabar com a violência social e estabelecer a paz global é quase impossível, e reduzir essa violência não é uma missão tão fácil. Porém, se houver conscientização, planejamento, comprometimento, cooperação e investimento de toda a sociedade e do Estado, acredita-se que seja possível e viável o seu combate e diminuição.

Finalizando, vale ressaltar que a diminuição da violência na educação e a melhoria do seu convívio dependem de vários níveis de atuação, desde os órgãos gestores centrais, que elaboram políticas e programas, até as escolas, que precisam estar mobilizadas para acolher essas iniciativas, com a ajuda da comunidade.

Ressalta-se aqui a colaboração da escola e da comunidade para a realização deste trabalho, sendo que as entrevistas foram realizadas de maneira tranquila e os participantes contribuíram com seriedade e disposição.

\section{Referências}

ARENDT, H. Sobre a violência. Rio de Janeiro: RelumeDumará, 1994.

BOGDAN, R.; BIKLEN, S. K. Qualitative Researche for Education. Boston: Allyn and Bacon. Inc., 1982.

CANDAU, V. M.; LUCINDA, M. da C.; NASCIMENTO, Maria das G. Escola e violência. Rio de Janeiro: DP\&A, 1999.

COLOMBIER, C. et al. A violência na escola. São Paulo: Summus, 1989.

CUBAS, Viviane de Oliveira. Violência nas escolas: como preveni-la. In: CUBAS, Viviane de Oliveira; RUTTI, Caren; ALVES, Renato. Violência na escola: um guia para pais e professores. São Paulo: Imprensa Oficial do Estado de São Paulo, 2006.

FANTE, Cleo. Fenômeno Bullying: como prevenir a violência nas escolas e educar para a paz. 2. ed. São Paulo: Verus, 2005. 
HAGUETTE, Teresa Maria Frota. Metodologias qualitativas na sociologia. 5. ed. Petrópolis: Vozes, 1997.

HOUAISS, Antônio; VILLAR, Mauro Salles. Dicionário Houaiss da Língua Portuguesa. Rio de Janeiro: Objetiva, 2009.

MINAYO, M. C. S. Pesquisa Social: teoria, método e criatividade. Rio de Janeiro: Vozes, 1995.

OLIVEIRA, Eny da Luz L. Gestão escolar e combate à violência: uma articulação necessária. Contra Pontos: Revista de Educação da Universidade do Vale do Itajaí, Itajaí, v. 8, n. 3, p. 491-505, set./ dez. 2008.

ROYER, ÉGIDE. A violência escolar e as políticas da formação de professores. In: DEBARBIEUX, Eric; BLAYA, Catherine (Org.). Violência nas escolas e políticas públicas. Brasília: UNESCO, 2002. p. 251-266.
SANTOS, José Vicente T. A violência na escola: conflitualidade social e ações civilizatórias. Educação $e$ Pesquisa, São Paulo, v. 27, n. 1, jan./jun. 2001.

UNIDOS na bagunça, Revista Veja, São Paulo, n. 22, p. 54-56, 29 de maio de 1996.

WAISELFISZ, Júlio Jacobo; MACIEL, Maria. Revertendo violências, semeando frutos: avaliação de impacto do Programa Abrindo Espaços no Rio de Janeiro e em Pernambuco. Brasília: UNESCO, 2003.

ZINATO, V. A. M.; MONTENEGRO. E. Orientações metodológicas de uma pesquisa qualitativa. Brasília, 2004. (texto digitado). 


\section{Para publicar na revista}

Universitas Humanas,

acesse $o$ endereço eletrônico www.publicacoesacademicas.uniceub.br. Observe as normas de publicação, para facilitar e agilizar o trabalho de edição. 